\title{
Examination of Changes in Flood Data in Australia
}

\author{
Elias Ishak ${ }^{1}$ and Ataur Rahman ${ }^{2, *}$ \\ 1 Penrith City Council, Penrith, NSW 2750, Australia \\ 2 School of Computing, Engineering and Mathematics, Western Sydney University, \\ Kingswood, NSW 2750, Australia \\ * Correspondence: a.rahman@uws.edu.au; Tel.: +61-473-60145
}

Received: 17 July 2019; Accepted: 15 August 2019; Published: 20 August 2019

check for updates

\begin{abstract}
This study performs a simultaneous evaluation of gradual and abrupt changes in Australian annual maximum (AM) flood data using a modified Mann-Kendall and Pettitt change-point detection test. The results show that AM flood data in eastern Australia is dominated by downward trends. Depending on the significance level and study period under consideration, about $8 \%$ to $33 \%$ of stations are characterised by significant trends, where over $85 \%$ of detected significant trends are downward. Furthermore, the change-point analysis shows that the percentages of stations experiencing one abrupt change in the mean or in the direction of the trend are in the range of $8 \%$ to $33 \%$, of which over $50 \%$ occurred in 1991, with a mode in 1995. Prominent resemblance between the monotonic trend and change-point analysis results is also noticed, in which a negative shift in the mean is observed at catchments that exhibited downward trends, and a positive shift in the mean is observed in the case of upward trends. Trend analysis of the segmented AM flood series based on their corresponding date indicates an absence of a significant trend, which may be attributed to the false detection of trends when the AM flood data are characterised by a shift in its mean.
\end{abstract}

Keywords: climate change; trend detection; Mann-Kendall test; Pettitt change-point test; annual maximum flood

\section{Introduction}

Extreme meteorological and hydrological events, in particular floods, have been and continue to be a natural disturbance regime of significant importance in terms of their influence on society, environment and economic activities [1]. Several major flood events have occurred throughout the world in recent years, and the perception is that extreme storms and floods have increased in terms of both intensity and frequency [2-5]. In light of climate change and natural climate variability, the severity and frequency of these extreme hydrological events and their associated damages are projected to increase significantly in future [6-9]. In addition, the current flood risk estimation techniques need to be revised to accommodate the non-stationarity encountered in the natural processes reported by various studies [10-15]. Changes in floods may be attributed to a range of different contributors, including natural changes in atmospheric forcings, catchment management and land-use changes (e.g., urbanisation, deforestation, regulations and storage) which can affect the translation of rainfall to runoff [6]. In addition, global warming which induces changes in atmospheric composition and in turn accelerated hydrological cycles can also be another potential contributor to the non-stationary behaviour of hydro-climatic variables [16].

Various studies have investigated changes in hydro-climatic variables across Australia. For instance, Plummer et al. [17], Smith et al. [18], Griffiths et al. [19], Gallant et al. [20], Alexander et al. [21], Pook et al. [22], Cai and Cowan [23], Taschetto and England [24], Alexander and Arblaster [25], Johnson and Sharma [26] and Laz et al. [27] (among many others) investigated trends in Australian rainfall and temperature data, and the common findings being that the northwest has experienced 
an increase in rainfall over the last 50 years, while much of eastern Australia and the far southwest have experienced a decrease. Changes in river flow are also evaluated. Chiew and McMahon [28] examined trends in annual streamflow of 30 unregulated Australian rivers to identify whether changes in streamflow are related to changes in climate. They did not find evidence of changes in streamflow resulting from climate change. Franks and Kuczera [12], Kiem et al. [29] and Micevski et al. [30] stratified the flood data from New South Wales according to the Interdecadal Pacific Ocean (IPO) phases, and they found that the post-1945 20-year flood exceeds the pre-1945 20-year flood for most of the analysed catchments. Pui et al. [31] found that the change in the annual maximum (AM) flood with change in IPO phase was mainly due to different antecedent wetness conditions preceding the AM rainfall event, while the AM rain was relatively stationary. Murphy and Timbal [32] reported that Victoria in south-east Australia has experienced extremely low streamflow since the mid-1990s. Cai and Cowan [33] have shown that the decrease in annual and/or seasonal streamflow totals in many locations of south-east Australia is not fully explained by the observed decrease in annual and/or seasonal rainfall totals. Stratification of Victorian streamflow according to multiple large-scale climate drivers, and antecedent catchment conditions, provides significantly different streamflow distributions according to Kiem and Verdon-Kidd [34]. Ishak et al. [9,35,36] investigated trends in AM flood data at 491 catchments using the Mann-Kendall test with consideration of the serial and inter-station correlation covering the whole of Australia as one study domain. Moreover, Ishak and Rahman [37] using monthly maximum, peak-over-threshold (POT) and AM flood data for 131 catchments in Victoria, Australia, found a resemblance in the results among these flow variables.

Detection of trends in hydro-climatic variables has also been the subject of numerous studies across the world [38-40]. Investigating a subset of Canadian low flows, Khaliq et al. [41] reported both increasing and decreasing trends in different parts of the country. Ehsanzadeh et al. [42] found that winter low flows are increasing in eastern Canada and southern British Columbia, whereas they are decreasing in western Canada; summer low flows are increasing in central Canada, southern British Columbia and Newfoundland, whereas they are decreasing in Yukon and northern British Columbia and also in eastern Ontario and Quebec. Novotny and Stefan [43] investigated the streamflow records from 36 gauging stations in five major river basins of Minnesota, USA for trend and correlations using the Mann-Kendall test and moving average method. The authors found that trends differed significantly from one river basin to another and became more prominent for shorter time windows. Furthermore, no sites were found to exhibit significant long-term trends when Villarini et al. [44] assessed the daily flow records from 55 monitoring stations in Europe. Kundzewicz et al. [45] investigated trends in annual maximum river flows using a worldwide data set of 195 flow records and found no evidence of increased maximum flows.

In all aforementioned studies in Australia, changes in hydrologic variables were performed under a monotonic trend or abrupt change assumption independently. This is mainly due to the fact that the current statistical trend tests cannot accommodate both assumptions, gradual and abrupt changes in mean or in the direction of trends, concurrently. Moreover, most of the previous studies on trends in Australian streamflow data emphasised on linking the identified changes to the inter-annual to inter-decadal climate variability (shifts to phase changes in climatic patterns) for a particular region of Australia without considering the impact of the flood data dependency (serially and spatially) on the trend outcomes. Exceptions are the investigations undertaken by [35,36]. A study solely of monotonic trends in a time series without considering the abrupt shifts in mean or change in direction of trends can produce deceptive outcomes if the time series is truly characterised by such behaviours [42]. The trend analysis results can only be meaningful only after identifying the abrupt shift and, in turn, partitioning the sample data to subsets with different trend behaviour. No work has so far been done in Australia, which takes into account abrupt changes in trend detection and performing trend analysis on the segments of flood records discriminated by possible change-points considering Australia as one study domain. This work thus extends the investigation by Ishak et al. $[35,36]$ whom only examined the 
monotonic trends in the Australian AM flood data. The findings of this study will contribute towards the growing body of knowledge on the nature of changes in Australian flood data.

\section{Study Area and Data}

For this study, the whole Australian continent has been selected as one study domain. Australia is the largest island continent in the southern hemisphere with wide range of climatic zones including the temperate regions in the south, through the arid expanses of the interior, to the tropical and equatorial regions of the north. As a consequence, the Australian climate experiences a high degree of spatial and temporal variability in relation to rainfall, temperature, streamflow and other hydro-climatic characteristics [46,47]. Generally, its central part (which covers about $75 \%$ of the continent) is arid to semi-arid, the northern part is hot and humid, and the southern part is dominated by winter rainfall. The average annual rainfall is below $600 \mathrm{~mm}$ over $80 \%$ of the continent, and below $300 \mathrm{~mm}$ over $50 \%$, making it the world's second driest continent [48]. Furthermore, the Australian climate is characterised by high inter-annual rainfall variability, which is linked to a variety of processes, mostly tropical in origin. These phenomena are known as the El Niño Southern Oscillation in the Pacific Ocean and Indian Ocean Dipole.

The AM flood data series used in this investigation have been prepared as part of the revision of the regional flood estimation methods in Australian Rainfall and Runoff [49]. This dataset represents the most comprehensive quality-controlled flood dataset (in terms of temporal and spatial coverage) that is currently available in Australia. These data have been subject to necessary quality control. After screening the AM time series and based on the quality and record length of the sample data, 491 stations, which were used in Ishak et al. [35,45], were also selected for this study. These catchments represent a wide range of geomorphology and topography (elevation ranging from $6 \mathrm{~m}$ to $1754 \mathrm{~m}$ ) over the continental scale (e.g., mountainous in the eastern and south-eastern parts of the continent, with flat terrain in western New South Wales and northern Victoria, with braided rivers in the Northern Territory and Northern Queensland, and with very old geology in north-western Western Australia [50]). In terms of land use, the selected catchments are predominantly forested in the south-eastern part, while the catchments in the northern part have little dense forest. Further information on these data can be found in $[1,51]$.

The AM flood record lengths of the selected stations are in the range of 30 years to 97 years with an average value of 38 years and a median value of 34 years. Some $73 \%$ of the stations have record lengths in the range $30-40$ years, $18 \%$ of the stations in the range $40-50$ years and only $9 \%$ of the stations greater than 50 years. The AM flood data values in this study are expressed in cubic meters per second $(\mathrm{cms})$. The catchment areas range from 1.3 to $4360 \mathrm{~km}^{2}$ with a median value of $280 \mathrm{~km}^{2}$ and a mean value of $374 \mathrm{~km}^{2}$. Some 57 catchments $(12 \%)$ are in the range of 1.3 to $50 \mathrm{~km}^{2}, 49$ catchments $(10 \%)$ are in the range of 50 to $100 \mathrm{~km}^{2}, 265$ catchments (54\%) are in the range of 101 to $500 \mathrm{~km}^{2}, 106$ catchments $(22 \%)$ are in the range of 501 to $1000 \mathrm{~km}^{2}$, and 15 catchments $(3 \%)$ are greater than $1000 \mathrm{~km}^{2}$. The geographical distribution of these stations is presented in Figure 1, which shows that most of the selected catchments are located near the coastlines which have the highest population density in Australia. The inland of Australia has relatively sparse geographical coverage of recording stations with good quality data and hence only a few stations have been selected from this part of Australia.

As the emphasis of this study is on identifying changes in streamflow data, a longer record length over different study periods is necessary to ensure derived conclusions regarding identified changes are meaningful. Hence, three separate study periods including 1955-2004 (50-year period), 1965-2004 (40-year period) and 1975-2004 (30-year period) were considered in the detection of changes in the AM flood data series. A total of 330, 77 and 21 stations were available for the 30-, 40- and 50-year study periods, respectively. The selected stations had continuous AM flood records over the entire length of the study period. These study periods were selected based on a trade-off between the total number of stations available and their record lengths. 


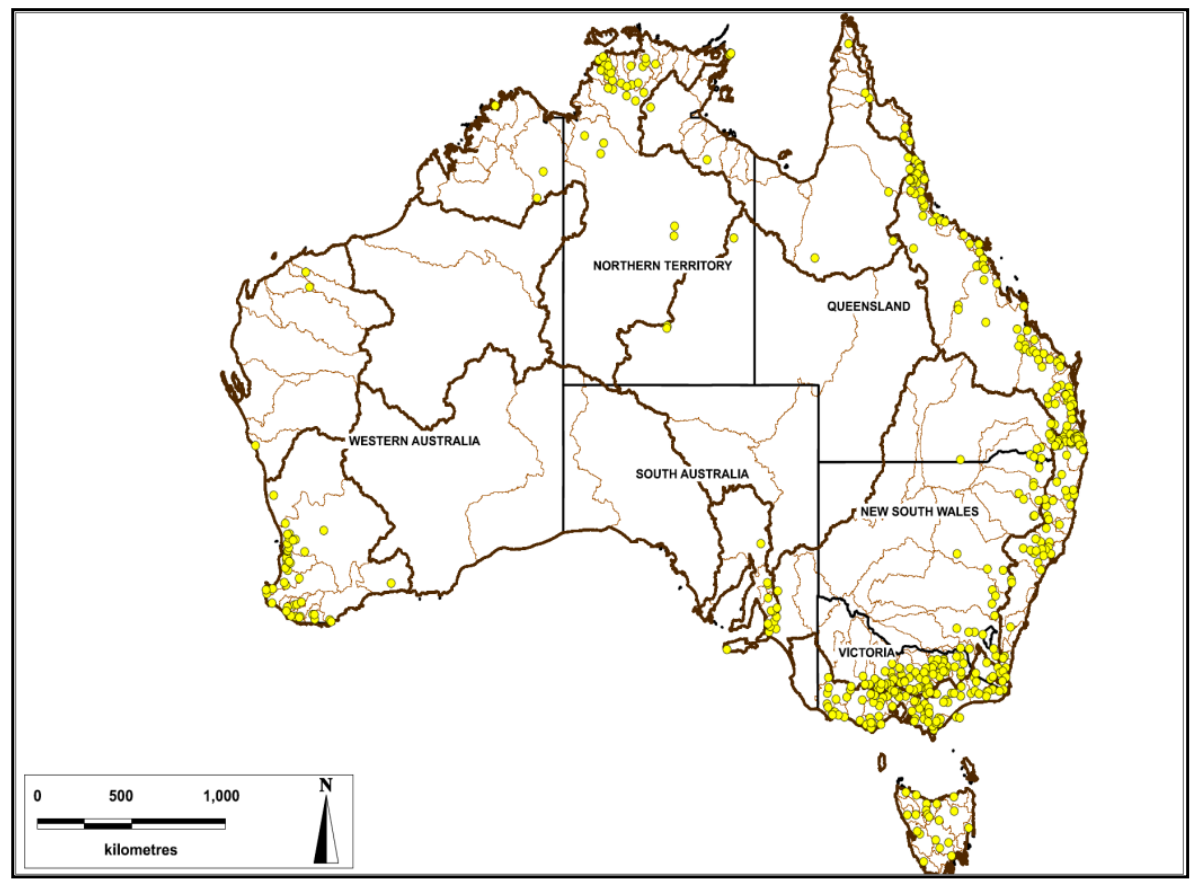

Figure 1. Geographical distribution of the selected 491 stations from all over Australia.

\section{Methodology}

\subsection{Mann-Kendall Test}

The most frequently used non-parametric test for identifying monotonic trends in hydro-meteorological time series is the Mann-Kendall (MK) test [52-54], which is a rank-based distribution-free method for identifying when trends are significant. The main reason for using non-parametric statistical tests is that compared to parametric statistical tests, the non-parametric ones are more robust for non-normally distributed data and censored data, which are frequently encountered in hydro-meteorological time series. This test has been adopted by a number of studies [35-38,43,55-57].

\subsection{Adaptation of Mann-Kendall Test to Account for Serial Correlation}

The adoption of the MK test has the advantage of being as powerful as regression-based tests in many cases, but it is not affected by outliers in the data [58]. While the test does not require the data to follow a normal distribution, the MK test does require serial independence of the data. The occurrence of the serial correlation in AM flood data can complicate the inference, as for example a positive serial correlation can enhance the estimated number of false positive outcomes from the MK test $[59,60]$. Therefore, it was important to adapt the MK test in order to take into consideration the impact of serial correlation in the AM flood data when assessing the significance of trends at local scales $(\alpha \mathrm{L})$ as failure to do so can result in erroneous conclusions [20]. Several approaches have been suggested to account for the impact of serial correlations on trend identification tests; one of the most widely used is the variance correction (VC) approach. The general theory behind the VC approach is that $n$ serially correlated observations contain the same information as $n^{*}(<n)$ uncorrelated observations (i.e., effective sample size (ESS)). Using the Monte Carlo simulation technique, Yue and Wang [61] assessed the ability of ESS to lessen the impact of serial correlation on the MK test. The authors found that if ESS is estimated from a de-trended time series, this can effectually reduce the influence of serial correlation on the MK test. Otherwise, if ESS is computed from sample data, which is characterised by a trend, ESS cannot properly eliminate the impact of serial correlation on the MK test. The proposed approach by Yue and Wang [61] was adopted in this study to evaluate the significance of a trend in a serially correlated AM flood data series using the following procedure: 
(1) The slope of trend of the AM flood data series is predicted using the non-parametric Sen's estimator of slope procedures developed by Sen (1968) [52]:

$$
\beta=\operatorname{median}\left(\frac{X_{k}-X_{j}}{k-j}\right)
$$

where $j<k$ and $\beta$ is the estimated slope of the trend.

(2) Assuming that the existing trend in AM flood data is monotonic and the data are detrended using the following expression:

$$
X_{t}^{\prime}=X_{t}-T_{t}=X_{t}-\beta t
$$

(3) Then the MK test variance is computed using the following equation:

$$
\operatorname{Var}(S)^{*}=\frac{n}{n^{*}} \operatorname{Var}(S)=C F \operatorname{Var}(S)
$$

where $n^{*}$ is the ESS and CF is the correction faction to account for serial correlation. The ESS $\left(n^{*}\right)$ is computed as:

$$
n^{*}=\frac{n}{1+\frac{2}{n} \sum_{k=1}^{n-1}(n-1) \rho_{k}}
$$

where $\rho_{k}$ is the lag- $k$ serial correlation coefficient of the AM flood data. The correction factor is, hence, estimated as:

$$
C F=\left\{\begin{array}{lll}
1+\frac{2}{n} \sum_{k=1}^{n-1}(n-k) \rho_{k} & \text { for } & k>1 \\
1+2 \frac{\rho_{1}^{n+1}-n \rho_{1}^{2}+(n-1) \rho_{1}}{n\left(\rho_{1}-1\right)^{2}} & \text { for } & k=1
\end{array} .\right.
$$

The modified standard MK statistic can then be defined as:

$$
Z^{*}=\frac{Z}{\sqrt{C F}} \text {. }
$$

\subsection{Pettitt Test for Change-Point Detection}

The Pettitt change-point approach developed by Pettitt [62] is commonly applied to detect a single change-point in a hydrological series or climate series with continuous data. In this study, the Pettitt change-point test was adopted to identify the presence and timing of non-stationarity in the form of an abrupt shift in the mean of the AM flood data series over time. The test is a non-parametric rank-based distribution-free test making it more robust in the presence of outliers and skewed data $[43,62]$. The test allows for detection of the time " $t$ " at which a possible shift in a time series may occur, by determining if the two means estimated for both subseries, before and after " $t$ ", are statistically different. The null hypothesis of the Pettitt test states that no abrupt shift exists in the time series at time " $t$ " and thus both means of the subseries are consistent. The alternative hypothesis is that change-points exists at time " $t$ ", in which $t=1, \ldots, n$ as all possible subdivisions of the time series are measured, since $t$ is unknown herein. The Pettitt test statistic is computed as:

$$
D_{i j}=\left\{\begin{array}{ccc}
+1 & \left(X_{i}-X_{j}\right)>0 \\
0 & \text { if } & \left(X_{i}-X_{j}\right)=0 \\
-1 & \left(X_{i}-X_{j}\right)<0
\end{array}\right.
$$

where $X_{i}$ and $X_{j}$ represent the magnitude of the AM flood data series at time $i$ and $j$ respectively, and $X_{i}$ precedes $X_{j}$ in time. To evaluate the test over the entire study period $(T)$ these $D$ statistics are jointed together as follows: 


$$
U_{t, T}=\sum_{i=1}^{t} \sum_{j=t+1}^{T} D_{i j} .
$$

Similar to the Mann-Whitney $U$ test the statistic $U_{t, T}$ measures if the two samples $X_{1}, \ldots, X_{t}$ and $X_{t+1}, \ldots, X_{T}$ are coming from the same population. The test statistic $U_{t, T}$ is appraised for all possible values of $t$ ranging from 1 to $T$. The following statistic is used to identify the time $t$ (year) which is presumably used to represent an abrupt shift in the time series:

$$
K_{T}=\max _{1 \leq t<T}\left|U_{t, T}\right| .
$$

If $K_{T}$ is significantly different from zero, then a change-point occurs in the year $t$ equivalent to the point in time for which the absolute value of $U_{t, T}$ is acquired. The significance of the test is assessed using the Monte Carlo resampling procedure to compute the corresponding $p$-values.

\section{Results}

\subsection{Trend Analysis under Monotonic Assumption}

The results of trend analysis are summarised in Table 1. Columns (1)-(3) of this table present the total number of tested stations as well as the number of general (irrespective to statistical significance) upward and downward trends for the three study periods. Note that the difference between the summation of numbers presented in columns (2) and (3) and that of total number of tested stations (column (1)) reflects the number of stations with no trends. A comparison of the number of stations characterised by decreasing trends (column (2)) with those characterised by increasing trends (column (3)) shows that regardless of the study period, the majority of the selected stations experienced downward trends during the specific observation period. For instance, the percentage of stations with negative trends varies from $67 \%$ to $78 \%$ while the percentage of stations with positive trends varies from $20 \%$ to $32 \%$. A high variability in the trend results is notably seen in Figure 2 that displays the modified MK Zs statistics for the selected 77 stations for the 40 -year study period. The overall trend results showed that the selected Australian stations were dominated by a negative trend in the AM flood data series with at least $67 \%$ (50-year study period) and at most $78 \%$ (30-year study period) of stations showing a negative trend.

Table 1. Results of trend analysis for different significance levels considering three study periods of

\begin{tabular}{|c|c|c|c|c|c|c|c|c|c|}
\hline \multirow{4}{*}{$\begin{array}{l}\text { Study } \\
\text { Period }\end{array}$} & \multirow{2}{*}{\multicolumn{3}{|c|}{ General Trends }} & \multicolumn{6}{|c|}{ Significant Trends } \\
\hline & & & & \multicolumn{3}{|c|}{$5 \%$ Significance Level } & \multicolumn{3}{|c|}{$10 \%$ Significance Level } \\
\hline & Total & Negative & Positive & Total & Negative & Positive & Total & Negative & Positive \\
\hline & (1) & (2) & (3) & (4) & (5) & (6) & (7) & (8) & (9) \\
\hline 30-year & 330 & 258 & 66 & 37 & 34 & 3 & 71 & 64 & 7 \\
\hline 40-year & 77 & 52 & 25 & 6 & 6 & 0 & 16 & 15 & 1 \\
\hline 50-year & 21 & 14 & 6 & 7 & 6 & 1 & 7 & 6 & 1 \\
\hline
\end{tabular}
annual maximum (AM) flood data.

The proportion of stations showing significant trends varies between $11 \%$ to $22 \%$ for the 30 -year study period, $8 \%$ to $21 \%$ for the 40 -year study period and $33 \%$ for the 50 -year study period depending on the significance level under consideration as shown in Table 1 (columns (4) and (7)). Regardless of the study period, there was a remarkable dominance in significant downward trends for the AM flood data series, as shown in Table 1 (columns (5) and (8)) at both $5 \%$ and $10 \%$ significance levels. This domination of downward trends was slightly stronger for the 30-year and 50-year study periods compared to 40-year period. Furthermore, the percentage of stations with significant downward 
trends was higher than the number expected to have occurred by chance at the significance levels of $5 \%$ and $10 \%$, respectively. For instance, considering the 30-year study period, 64 stations out of $330(19 \%)$ showed a significant downward trend. This was greater than 33 stations which would be expected to exhibit a trend by chance at the $10 \%$ significance level. On the other hand, and despite the significance level under assessment, the number of stations showing statistically significant upward trends varies between $1 \%$ to $5 \%$, as shown in Table 1 (columns (6) and (9)). These percentages of stations with significant upward trends were considered to be statistically insignificant as they were smaller than the likely number to occur by chance at the considered significance levels. Therefore, it is prominent that the percentages of stations exhibiting significant downward trends exceeded what would be expected due to random variability regardless of the significance levels under consideration for the three study periods, and thus the results do imply that trends found in the AM flood data series, and more precisely that the Australian AM flood data series, are dominated by a downward trend.

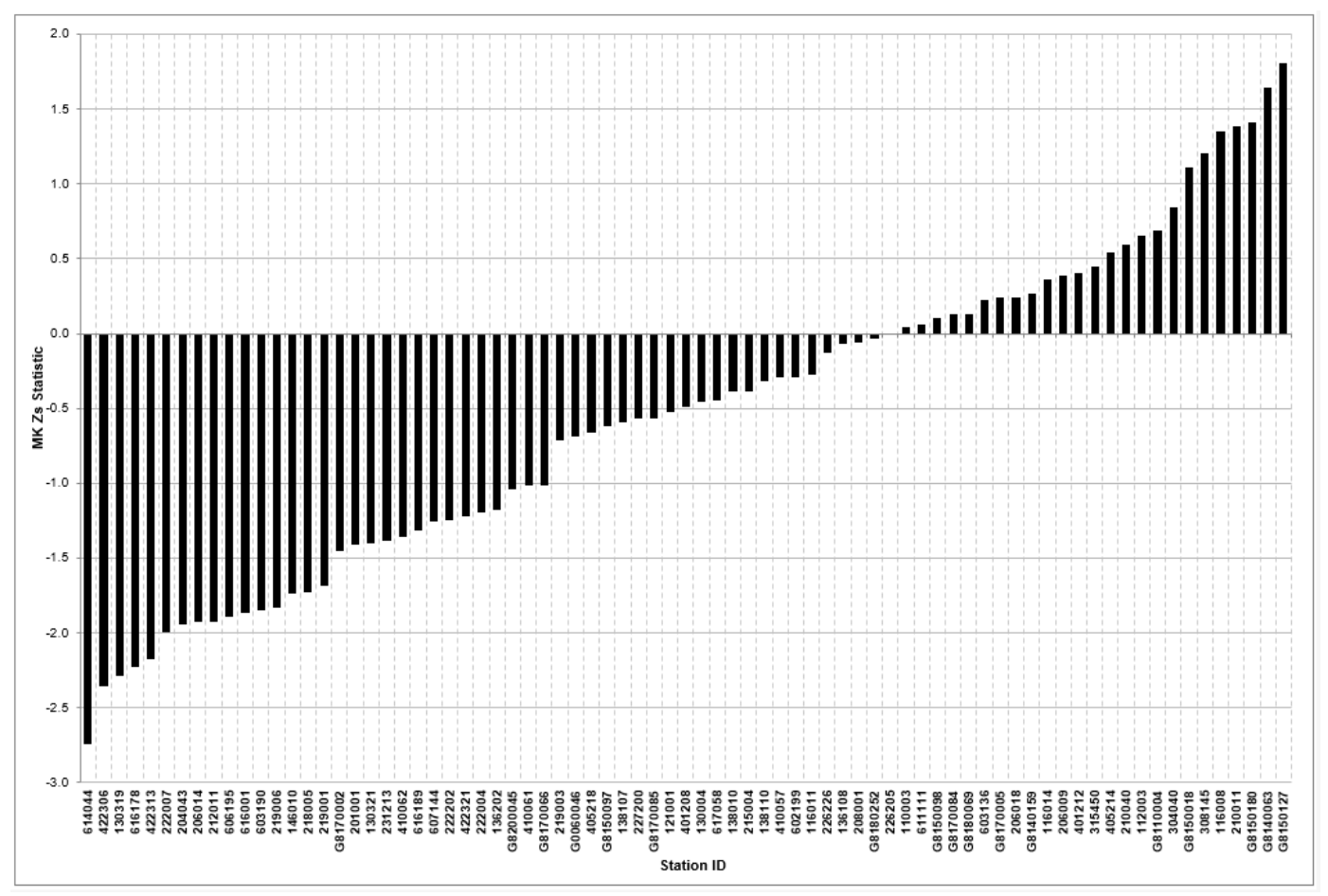

Figure 2. Mann-Kendall (MK) test Zs statistics for individual stations for the 40-year study period.

\subsection{Change-Point Analysis}

The Pettitt change-point test was used in this investigation to identify the presence and timing of non-stationarity in the form of an abrupt shift in the mean of the AM flood data over the three study periods. Regardless of the study periods under consideration, the Pettitt change-point analysis results show a significant negative shift in the mean of the magnitude of the AM flood data at both significance levels of $5 \%$ and $10 \%$. For instance, 66 stations experienced a significant negative shift while 8 stations exhibited a significant positive shift at significance level of $10 \%$ for the 30 -year study period. Similarly, for the 40-year study period, 12 of the shifts are negative and two are positive; and for the 50-year study period, 6 stations exhibited a significant negative shift and one catchment a positive shift.

Taking into consideration the year in which these abrupt shifts in the mean occurred, the sites with significant change-points were categorised into six groups as presented in Table 2. The selection of these time interval periods was established from the review of the results found in the literature. For instance, previous studies have identified a rainfall deficiency in the mid 80s and 90s $[20,32,63,64]$. As illustrated in Figure 3, sites exhibiting significant change-points in the mean flood magnitude tended to be scattered along the coastlines along the continent, although sites in close proximity often showed 
shifts around the same time period. The timing of these abrupt shifts is particularly critical when investigating the possible causes of non-stationarity in the AM flood data, whether anthropogenic or due to natural climate variability. Table 3 outlines the number of stations showing significant change-points in each considered time interval. These results were consistent with the literature of the abovementioned studies. Namely, the highest number of sites with change-points occurred in the period from 1991 to 1995 followed by the period from 1996 to 2000.

Table 2. Number of stations exhibiting change-points within the selected time intervals as identified by the Pettitt test.

\begin{tabular}{ccccccc}
\hline \multicolumn{7}{c}{ Number of Sites with Change-Point } \\
\hline Study Period & $\mathbf{1 9 7 0 - 1 9 7 5}$ & $\mathbf{1 9 7 6 - 1 9 8 0}$ & $\mathbf{1 9 8 1 - 1 9 8 5}$ & $\mathbf{1 9 8 6 - 1 9 9 0}$ & $\mathbf{1 9 9 1 - 1 9 9 5}$ & $\mathbf{1 9 9 6 - 2 0 0 0}$ \\
\hline 30-year & - & - & 5 & 6 & 42 & 21 \\
40-year & 2 & 2 & 1 & 2 & 7 & - \\
50-year & 1 & 4 & - & - & 2 & - \\
\hline
\end{tabular}

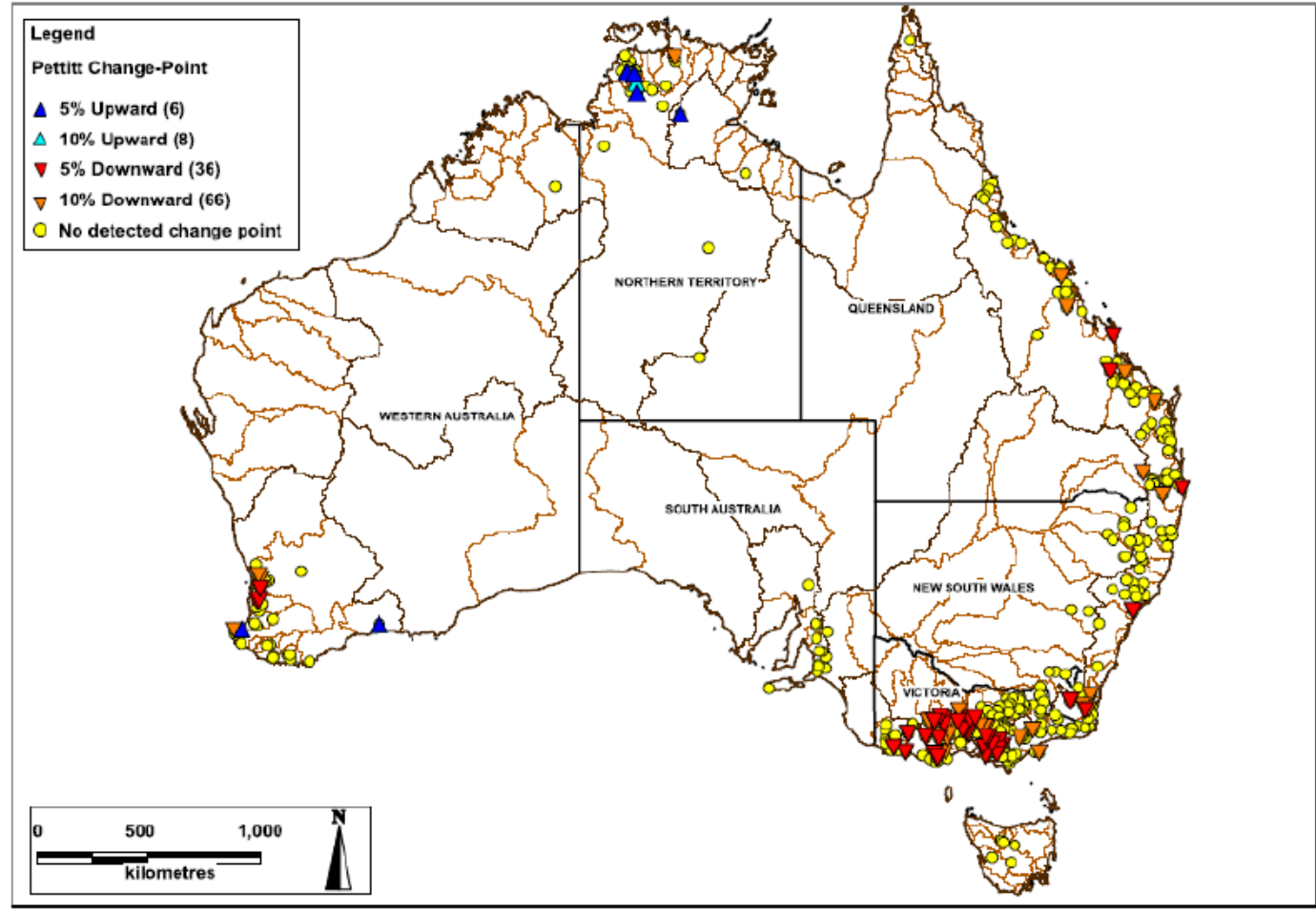

Figure 3. Spatial distributions of stations with change-points in the mean AM flood data for the 30-year study period. Upright (inverted) triangles represent significant positive (negative) shifts.

Table 3. Number of stations exhibiting non-stationarity in the form of trends and change-points, along with the number of stations which show simultaneously trends and abrupt shifts and the remaining number of stations exhibiting either trends or change-points at the $10 \%$ significance level.

\begin{tabular}{|c|c|c|c|c|c|}
\hline Study Period & Trend (1) & Change-Point (2) & Common (3) & $\begin{array}{c}\text { Remaining } \\
\text { Only Trend (4) }\end{array}$ & $\begin{array}{l}\text { Remaining Only } \\
\text { Change-Point (5) }\end{array}$ \\
\hline \multicolumn{6}{|c|}{ At the Significance Level of $5 \%$} \\
\hline 30-year & 37 & 42 & 25 & 12 & 16 \\
\hline 40-year & 6 & 6 & 3 & 3 & 3 \\
\hline 50-year & 7 & 7 & 6 & - & 1 \\
\hline \multicolumn{6}{|c|}{ At the Significance Level of $10 \%$} \\
\hline 30-year & 71 & 74 & 43 & 28 & 31 \\
\hline 40-year & 16 & 14 & 11 & 5 & 3 \\
\hline 50-year & 7 & 7 & 7 & - & - \\
\hline
\end{tabular}




\section{Spatial Distribution of Observed Trends}

Owing to similarity of obtained results for the different selected study periods and for the sake of brevity, only the spatial patterns of observed trends across Australia of the 30-year study period are discussed here. The spatial distribution of identified significant monotonic trends is presented in Figure 4 that provides some information on the location of AM flood data series characterised by upward and downward trends. In this figure, the stations that exhibited significant upward and downward trends at the relevant significance level are represented by upright and inverted triangles, respectively, and the stations showing no trend are represented by the crossed yellow circles. Similarly, Figure 3 shows the locations of the stations for which change-points were detected and the direction of the associated shift in the mean for the 30-year study period. The parenthesised values within both figures' legends corresponded to the number of sites illustrated for their relevant categories. For instance, at the significance level of 5\%, 36 stations experienced a significant negative shift and 6 stations exhibited a significant positive shift for the 30-year study period. Prominent from Figures 3 and 4 is the correspondence in the distribution of the stations with significant downward trends and significant negative shifts along the eastern coast, the south-eastern and south-western regions across Australia. The upward trend and positive shift were more visible in the north-western region of the country. Similar distribution was also observed for the 40-year and 50-year study periods. Similar findings are also reported in [35,45].

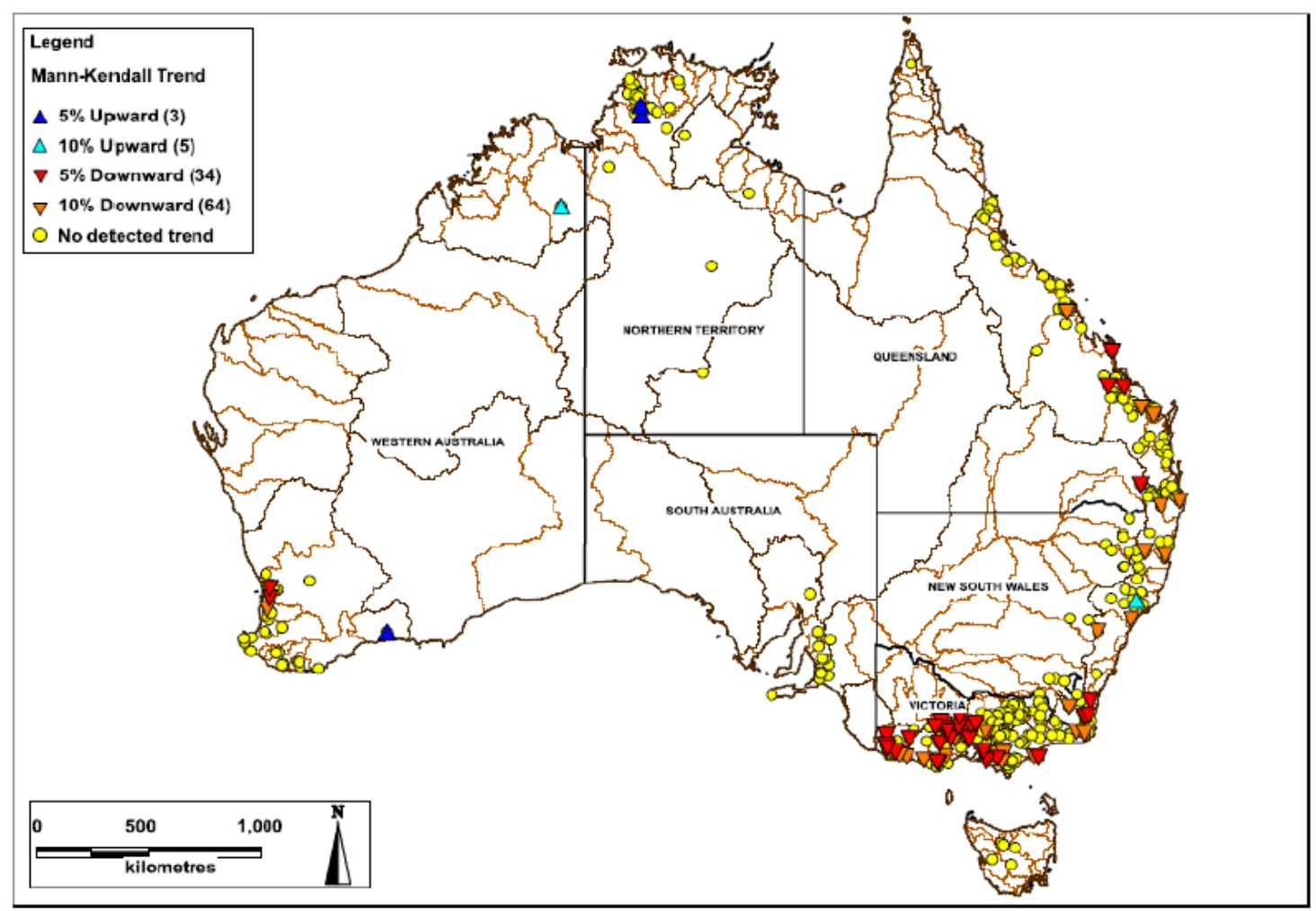

Figure 4. Spatial distributions of stations showing significant trends in Australian AM flood data for the 30-year study period. Upright (inverted) triangles represent stations with a significant increasing (decreasing) trends.

\section{Discussion}

The change-point analysis results are comparable to the trend results for the majority of the examined stations where a significant gradual trend was identified as displayed in Table 3. In the manner that a negative shift in the mean was observed at stations that exhibited a downward trend and a positive shift in the mean was observed in the case of an upward trend as demonstrated in 
Figure 5. Columns (1) and (2) of Table 3 present a comparison between the total number of stations that exhibit a significant trend and change-point; while the number of stations that are common between both tests is presented in column (3). For instance, of the 42 (74) stations (column (2)) recognised to have a change-point, 25 (43) stations (column (3)) also presented a significant trend over the entire 30 -year study period of record at the significance level of 5\% (10\%). Similar outcomes were obtained for the 40-year study period, whilst for the 50-year study period the same stations identified to have a significant trend experienced an abrupt shift in the mean of the AM flood data (column (3)). This harmony in detecting change results between the two tests may arguably claim that the presence of an abrupt shift in the mean of AM flood data could have impacted the results of the trend test, and lead to spurious conclusions [41].
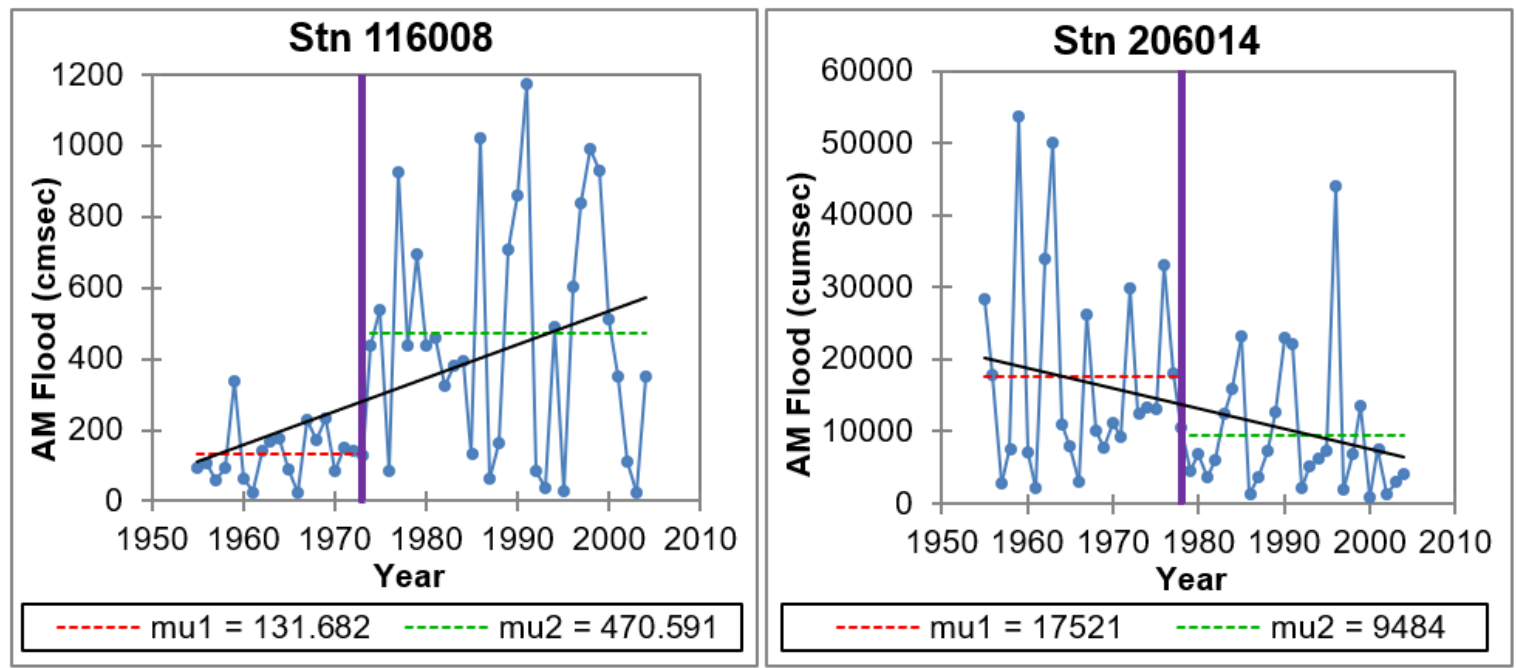

Figure 5. Illustration of the correspondence between the Pettitt change-point and MK test results.

Accordingly, for those stations shown in Table 3 (column (3)) presenting a significant change-point in the mean of the AM flood data series herein, a trend analysis was undertaken independently a second time for each of the subseries before and after the shift. This approach was adopted in similar studies to assess the non-stationarity behaviour of hydrological variables [41,65]. Trend analysis of the segmented AM flood series based on their corresponding change-point date indicates an absence of a significant trend; in that significant trends were not identified in either subseries (before or after the shift) for all the stations (in question) analysed for the three study periods at both significance levels of $5 \%$ and $10 \%$. This might propose that the existence of change-points impacted the trend results, falsely detecting monotonic trends when an abrupt shift in the mean of the distribution was more likely. However, these results need to be interpreted with precaution, as in most of the cases the segmented time series have a very short record (less than 15 years) that could mask the identification of gradual trends (e.g., trend is very weak or just started).

The aforementioned outcomes must be interpreted in conjunction with the results displayed in columns (4) and (5) of Table 3. These columns show the number of stations that are exclusively exhibiting either a significant monotonic trend or abrupt shift in the mean of AM flood data. The results presented in column (4), such as out of the $11 \%$ (22\%) of the stations showing significant trend, $31 \%(41 \%)$ are merely exhibiting monotonic trends for the 30-year study period at the significance level of 5\% (10\%). For the 40-year study period, 50\% (30\%) of the stations having significant trends are solely exhibiting a monotonic trend at the significance level of 5\% (10\%). Whereas for the 50-year study periods, the stations experiencing a significant monotonic trend also experienced abrupt shifts. Therefore, and depending on whether the monotonic trend assumption embraces, the on-site interpretation of results may vary or even lead to contradictory conclusions. These findings add to the difficultly to 
state whether the identified non-stationarity in the Australian AM flood manifests in most cases as a change-point or gradual trend, and to draw a generalised conclusion.

The dominance of downward trends in AM flood data in eastern Australia as found in this study resembles the finding of Do et al. [66]. The decreasing trend in flood data also compares very well with the trends of extreme rainfall data in this part of Australia [67]. These studies also show that northern Australia is dominated by an increasing trend in both flood and rainfall data. The observed decreasing trend in AM flood data in eastern Australia is mainly due to decreasing trends in extreme rainfall data as noted by $[66,67]$. Smaller rainfall and longer dry spells affect catchment antecedent conditions, e.g., a drier catchment produces a relatively smaller runoff.

\section{Conclusions}

The non-stationarity characteristics (gradual trend and abrupt shift in the mean of annual maximum (AM) flood data in Australia) were assessed using the Mann-Kendall (MK) and Pettitt change-point tests. Three study periods were considered here representing 30, 40 and 50 years of AM flood data. The Pettitt change-point test was adopted to identify the potential abrupt shift in the mean of the AM flood data, along with the direction and timing of the shift. The potential impact of change-points on the trend test was also investigated.

Overall, it was found that the Australian AM flood data was characterised by a significant downward trend. The percentage of stations exhibiting significant downward trends exceeds what is expected due to random variability, and thus the results confirm that trends do exist in AM flood data in Australia, and more precisely, the Australian AM flood data are dominated by a downward trend.

The results of change-point analysis were comparable to that of the trend analysis, e.g., a negative shift in the mean was observed at catchments that exhibit a downward trend, and a positive shift in the mean was observed in the case of upward trends. A subsequent trend analysis of the subseries (for those catchments identified with a significant shift in the mean of the AM flood), before and after the shift, and based on their respective change-point period, demonstrates that none of these subseries shows a significant trend. It was also found that the number of stations showing an abrupt shift in the mean of Australian AM flood data were equal or greater than the number of catchments with monotonic trends. Another important finding was the identification of a good number of stations exhibiting solely significant monotonic trends or abrupt shifts. From these results it is difficult to confirm whether the identified non-stationarity in the Australian AM flood data is due to gradual trends or change-points.

The observed downward trends in the AM flood data were found to be dominant along the eastern, south-eastern and south-western parts, and an upward trend was observed in the north-western part of Australia.

Author Contributions: E.I. conducted the analysis, prepared the draft of the manuscript. A.R. designed the research idea, reviewed and edited the manuscript.

Funding: This research received no external funding.

Acknowledgments: The authors acknowledge Engineers Australia, Department of Sustainability and Environment (Victoria), George Kuczera, Ashish Sharma, Khaled Haddad, Seth Westra and Erwin Weinmann for their input to the project and the three reviewers for their constructive comments, which have helped to improve the paper significantly.

Conflicts of Interest: The authors declare no conflict of interest.

\section{References}

1. Aziz, K.; Rahman, A.; Fang, G.; Shreshtha, S. Application of Artificial Neural Networks in Regional Flood Frequency Analysis: A Case Study for Australia. Stoch. Environ. Res. Risk Assess. 2014, 28, 541-554. [CrossRef]

2. Milly, P.; Wetherald, R.; Dunne, K.; Delworth, T. Increasing risk of great floods in a changing climate. Nature 2002, 415, 514-517. [CrossRef] [PubMed] 
3. Svensson, C.; Kundzewicz, Z.W.; Maurer, T. Trend detection in river flow series: 2. Flood and low-flow index series. Hydrol. Sci. J. 2005, 50. [CrossRef]

4. Seneviratne, S.I.; Nicholls, N.; Easterling, D.; Goodess, C.M.; Kanae, S.; Kossin, J.; Luo, Y.; Marengo, J.; McInnes, K.; Rahimi, M.; et al. Changes in climate extremes and their impacts on the natural physical environment. In Managing the Risks of Extreme Events and Disasters to Advance Climate Change Adaptation; A Special Report of Working Groups I and II of the Intergovernmental Panel on Climate Change (IPCC); Field, C.B., Barros, V., Stocker, T.F., Qin, D., Dokken, D.J., Ebi, K.L., Mastrandrea, M.D., Mach, K.J., Plattner, G.-K., Allen, S.K., Eds.; Cambridge University Press: Cambridge, UK; New York, NY, USA, 2012; pp. 109-230.

5. Paul, B.K.; Mahmood, S. Selected physical parameters as determinants of flood fatalities in Bangladesh, 1972-2013. Nat. Hazards 2016, 83, 1703. [CrossRef]

6. Intergovernmental Panel on Climate Change (IPCC). Climate Change 2007: Mitigation of Climate Change; Contribution of Working Group III to the Fourth Assessment Report of the Intergovernmental Panel on Climate Change; Metz, B., Davidson, O., Bosch, P., Dave, R., Meyer, L., Eds.; Cambridge University Press: New York, NY, USA, 2007.

7. Blunden, J.; Derek, S.A. State of the Climate 2012; Commonwealth Scientific and Industrial Research Organisation (CSIRO): Canberra, Australia; The Australian Government Bureau of Meteorology (BOM): Melbourne, Australia, 2012.

8. Mamoon, A.A.; Jeorgensen, N.E.; Rahman, A.; Qasem, H. Design Rainfall in Qatar: Sensitivity to Climate Change Scenarios. Nat. Hazards 2016, 81, 1797-1810. [CrossRef]

9. Ishak, E.; Haddad, K. Zaman and Rahman Scaling property of regional floods in New South Wales Australia. Nat. Hazards 2011, 58, 1155-1167. [CrossRef]

10. Hirschboeck, K.K.; Ely, L.L.; Maddox, R.A. Hydroclimatology of Meteorologic Floods, Inland Flood Hazards; Wohl, E.E., Ed.; Cambridge University Press: Cambridge, UK; New York, NY, USA, 2000; pp. 39-72.

11. Jain, S.; Lall, U. Floods in a changing climate: Does the past represent the future? Water Resour. Res. 2001, 37, 3193-3205. [CrossRef]

12. Franks, S.W.; Kuczera, G. Flood frequency analysis: Evidence and implications of secular climate variability, New South Wales. Water Resour. Res. 2002, 38, 1062. [CrossRef]

13. Khaliq, M.N.; Ouarda, T.B.M.J.; Ondo, J.C.; Gachon, P.; Bobée, B. Frequency analysis of a sequence of dependent and/or non-stationary hydro-meteorological observations: A review. J. Hydrol. 2006, 329, 534-552. [CrossRef]

14. Raff, D.; Pruitt, T.; Brekke, L. A framework for assessing flood frequency based on climate projection information. Hydrol. Earth Syst. Sci. 2009, 13, 2119. [CrossRef]

15. Shaoo, S.N.; Sreeja, P. Relationship between peak rainfall intensity (PRI) and maximum flood depth (MFD) in an urban catchment of Northeast India. Nat. Hazards 2016, 83, 1527. [CrossRef]

16. Kundzewicz, Z.W. Searching for change in hydrological data-Editorial. Hydrol. Sci. J. 2004, 49, 3-6. [CrossRef]

17. Plummer, N.; Salinger, M.J.; Nicholls, N.; Suppiah, R.; Hennessy, K.J.; Leighton, R.M.; Trewin, B.; Page, C.M.; Lough, J.M. Changes in climate extremes over the Australian region and New Zealand during the twentieth century. Clim. Chang. 1999, 42, 183-202. [CrossRef]

18. Smith, I. An Assessment of Recent Trends in Australian Rainfall. Aust. Meteorol. Mag. 2004, 53, $163-173$.

19. Griffiths, G.M.; Chambers, L.E.; Haylock, M.R.; Manton, M.J.; Nicholls, N.; Baek, H.J.; Choi, Y.; Della-Marta, P.M.; Gosai, A.; Iga, N.; et al. Change in mean temperature as a predictor of extreme temperature change in the Asia-Pacific region. Int. J. Climatol. 2005, 25, 1301-1330. [CrossRef]

20. Gallant, A.J.E.; Hennessy, K.J.; Risbey, J. Trends in rainfall indices for six Australian regions: 1910-2005. Aust. Meteorol. Mag. 2007, 56, 223-239.

21. Alexander, L.V.; Hope, P.; Collins, D.; Trewin, B.; Lynch, A.; Nicholls, N. Trends in Australia's climate means and extremes: A global context. Aust. Meteorol. Mag. 2007, 56,1-18.

22. Pook, M.; Lisson, S.; Risbey, J.; Ummenhofer, C.; McIntosh, P.; Rebbeck, M. The autumn break for cropping in southeast Australia: Trends, synoptic influences and impacts on wheat yield. Int. J. Climatol. 2009, 29, 2012-2026. [CrossRef]

23. Cai, W.; Cowan, T. Dynamics of late autumn rainfall reduction over southeastern Australia. Geophys. Res. Lett. 2008, 35, L09708. [CrossRef] 
24. Taschetto, A.S.; England, M.H. An analysis of late twentieth century trends in Australian rainfall. Int. J. Climatol. 2009, 29, 791-807. [CrossRef]

25. Alexander, L.V.; Arblaster, J.M. Assessing trends in observed and modelled climate extremes over Australia in relation to future projections. Int. J. Climatol. 2009, 29, 417-435. [CrossRef]

26. Johnson, F.; Sharma, A. A Comparison of Australian Open Water Body Evaporation Trends for Current and Future Climates Estimated from Class A Evaporation Pans and General Circulation Models. J. Hydrometeorol. 2010, 11, 105-121. [CrossRef]

27. Laz, O.U.; Rahman, A.; Yilmaz, A.; Haddad, K. Trends in sub hourly, sub daily and daily extreme rainfall events in eastern Australia. J. Water Clim. Chang. 2014, 5, 667-675. [CrossRef]

28. Chiew, F.H.; McMahon, T.A. Detection of trend or change in annual flow of Australian rivers. Int. J. Climatol. 1993, 13, 643-653. [CrossRef]

29. Kiem, A.S.; Franks, S.W.; Kuczera, G. Multi-decadal variability of flood risk. Geophys. Res. Lett. 2003, 30, 1035. [CrossRef]

30. Micevski, T.; Franks, S.W.; Kuczera, G. Multidecadal variability in coastal eastern Australian flood data. J. Hydrol. 2006, 327, 219-225. [CrossRef]

31. Pui, A.; Lal, A.; Sharma, A. How does the Interdecadal Pacific Oscillation affect design floods in Australia? Water Resour. Res. 2011, 47, W05554. [CrossRef]

32. Murphy, B.F.; Timbal, B. A review of recent climate variability and climate change in south-eastern Australia. Int. J. Climatol. 2008, 28, 859-879. [CrossRef]

33. Cai, W.; Cowan, T. Evidence of impacts from rising temperature on inflows to the Murray-Darling Basin. Geophys. Res. Lett. 2008, 35, L07701. [CrossRef]

34. Kiem, A.S.; Verdon-Kidd, D.C. Climatic drivers of Victorian streamflow: Is ENSO the dominant influence? Aust. J. Water Resour. 2009, 13, 17-30. [CrossRef]

35. Ishak, E.H.; Rahman, A.; Westra, S.; Sharma, A.; Kuczera, G. Evaluating non-stationrity of Australian annual maximum flood. J. Hydrol. 2013, 494, 134-145. [CrossRef]

36. Ishak, E.; Rahman, A.; Westra, S.; Sharma, A.; Kuczera, G. Preliminary Analysis of Trends in Australian Flood Data. World Environ. Water Resour. Congr. 2010, 2010, 115-124.

37. Ishak, E.; Rahman, A. Detection of changes in flood data in Victoria, Australia over 1975-2011. Hydrol. Res. 2015, 46, 763-776. [CrossRef]

38. Douglas, E.M.; Vogel, R.M.; Kroll, C.N. Trends in floods and low flows in the United States: Impact of spatial correlation. J. Hydrol. 2000, 240, 90-105. [CrossRef]

39. Groisman, P.Y.; Knight, R.W.; Karl, T.R. Heavy precipitation and high streamflow in the contiguous United States: Trends in the twentieth century. Bull. Am. Meteorol. Soc. 2001, 82, 219-246. [CrossRef]

40. Birsan, M.V.; Molnar, P.; Burlando, P.; Pfaundler, M. Streamflow trends in Switzerland. J. Hydrol. 2005, 314, 312-329. [CrossRef]

41. Khaliq, M.N.; Ouarda, T.B.M.J.; Gachon, P.; Sushama, L. Temporal evolution of low flow regimes in Canadian rivers. Water Resour. Res. 2008, 44, W08436. [CrossRef]

42. Ehsanzadeh, E.; Ouarda, T.B.M.J.; Saley, H.M. A simultaneous analysis of gradual and abrupt changes in Canadian low streamflow. Hydrol. Process. 2011, 25, 727-739. [CrossRef]

43. Novotny, E.V.; Stefan, H.G. Stream flow in Minnesota: Indicator of climate change. J. Hydrol. 2007, 334, 319-333. [CrossRef]

44. Villarini, G.; Smith, J.A.; Serinaldi, F.; Ntelekos, A.A. Analyses of seasonal and annual maximum daily discharge records for central Europe. J. Hydrol. 2011, 399, 299-312. [CrossRef]

45. Kundzewicz, Z.W.; Graczyk, D.; Maurer, T.; Pinskwar, I.; Radziejewski, M.; Svensson, C.; Szwed, M. Trend detection in river flow series: 1. Annual maximum flow. Hydrol. Sci. J. 2005, 50, 797-810. [CrossRef]

46. Haddad, K.; Rahman, A.; Green, J. Design Rainfall Estimation in Australia: A Case Study using L moments and Generalized Least Squares Regression. Stoch. Environ. Res. Risk Assess. 2011, 25, 815-825. [CrossRef]

47. Loveridge, M.; Rahman, A. Quantifying uncertainty in rainfall-runoff models due to design losses using Monte Carlo simulation: A case study in New South Wales, Australia. Stoch. Environ. Res. Risk Assess. 2014, 28, 2149-2159. [CrossRef]

48. Holper, P.N.; CSIRO. Climate Change Science Information Paper: Australian Rainfall-Past, Present and Future; CSIRO: Aspendale, Victoria, Australia, 2011; pp. 1-18. 
49. Institution of Engineers Australia (I. E. Aust.). Australian Rainfall and Runoff-A Guide to Flood Estimation; I. E. Aust.: Canberra, Australia, 2001.

50. GWA (Government of Western Australia). Department of Mines and Petroleum Geology of Western Australia. 2013. Available online: http://www.dmp.wa.gov.au/11636.aspx (accessed on 17 January 2013).

51. Haddad, K.; Rahman, A.; Weinmann, P.E.; Kuczera, G.; Ball, J.E. Streamflow data preparation for regional flood frequency analysis: Lessons from south-east Australia. Aust. J. Water Resour. 2010, 14, 17-32. [CrossRef]

52. Sen, P.K. Estimates of the regression coefficient based on Kendall's tau. J. Am. Stat. Assoc. 1968, 63, 1379-1389. [CrossRef]

53. Mann, H.B. Non-parametric tests against trend. Econometrica 1945, 13, 245-259. [CrossRef]

54. Kendall, M.G. Rank Correlation Methods, 4th ed.; Charles Griffin \& Co: Griffin, London, UK, 1975.

55. Burn, D.H.; Hag Elnur, M.A. Detection of hydrologic trends and variability. J. Hydrol. 2002, 255, 107-122. [CrossRef]

56. Yue, S.; Pilon, P.J.; Phinney, B.; Cavadias, G. The influence of autocorrelation on the ability to detect trend in hydrological series. Hydrol. Process. 2002, 16, 1807-1829. [CrossRef]

57. Collins, M.J. Evidence for changing flood risk in New England since the late 20th Century. J. Am. Water Resour. Assoc. 2009, 45, 279-290. [CrossRef]

58. Helsel, D.R.; Hirsch, R.M. Statistical Methods in Water Resources; Elsevier: Amsterdam, The Netherlands, 1992.

59. Von Storch, H. Misuses of statistical analysis in climate research. In Analysis of Climate Variability: Applications of Statistical Techniques; Von Storch, H., Navarra, A., Eds.; Springer: Berlin, Germany, 1995; pp. 11-26.

60. Khaliq, M.N.; Ouarda, T.B.M.J.; Gachon, P.; Sushama, L.; St-Hilaire, A. Identification of hydrological trends in the presence of serial and cross correlations: A review of selected methods and their application to annual flow regimes of Canadian rivers. J. Hydrol. 2009, 368, 117-130. [CrossRef]

61. Yue, S.; Wang, C.Y. The Mann-Kendall test modified by effective sample size to detect trend in serially correlated hydrological series. Water Resour. Manag. 2004, 18, 201-218. [CrossRef]

62. Pettitt, A. A non-parametric approach to the change-point problem. Appl. Stat. 1979, 28, 126-135. [CrossRef]

63. Ummenhofer, C.C.; England, M.H.; McIntosh, P.C.; Meyers, G.A.; Pook, M.J.; Risbey, J.S.; Gupta, A.S.; Taschetto, A.S. What causes southeast Australia's worst droughts? Geophys. Res. Lett. 2009, 36, L04706. [CrossRef]

64. Ummenhofer, C.C.; Sen Gupta, A.; Taschetto, A.S.; England, M.H. Modulation of Australian precipitation by meridional gradients in East Indian Ocean sea surface temperature. J. Clim. 2009, 22, 5597-5610. [CrossRef]

65. Villarini, G.; Smith, J.A. Flood peak distribution for eastern United States. Water Resour. Res. $2010,46$. [CrossRef]

66. Hong, X.D.; Westra, S.; Leonard, M. A global-scale investigation of trends in annual maximum streamflow. J. Hydrol. 2017, 552, 28-43.

67. Hajani, E.; Rahman, A. Characterising Changes in Rainfall: A Case Study for New South Wales, Australia. Int. J. Climatol. 2018, 38, 1452-1462. [CrossRef]

(C) 2019 by the authors. Licensee MDPI, Basel, Switzerland. This article is an open access article distributed under the terms and conditions of the Creative Commons Attribution (CC BY) license (http://creativecommons.org/licenses/by/4.0/). 